\title{
Protective Effect of Tragopogon Graminifolius DC Against Ethanol Induced Gastric Ulcer
}

\author{
Mohamad Hosein Farzaei ${ }^{1,2}$, Mozafar Khazaei ${ }^{1,{ }^{*}}$, Zahra Abbasabadei ${ }^{3}$,Maryam Feyzmahdavi ${ }^{3}$, \\ Gholam Reza Mohseni ${ }^{4}$ \\ ${ }_{2}^{1}$ Fertility and Infertility Research Center, Kermanshah University of Medical Sciences, Kermanshah, IR Iran \\ 2 Department of Traditional Pharmacy, Faculty of Traditional Medicine, Tehran University of Medical Science, Tehran, IR Iran \\ 3 Faculty of Pharmacy, Kermanshah University of Medical Sciences, Kermanshah, IR Iran \\ 4 Akhtar Hospital, Shahid Beheshti University of Medical Sciences, Tehran, IR Iran \\ ${ }^{*}$ Corresponding author: Mozafar Khazaei, Corresponding author: Mozafar Khazaei, Fertility and Infertility Research Center, Kermanshah University of Medical Sciences, Kerman- \\ shah, IR Iran, Tel:+98-8314276417-21, Fax:+98-8314281563, E-mail:mkhazaei1345@yahoo.com.
}

Received: August 22, 2012; Revised: January 02, 2013; Accepted: March 10, 2013

Background: Gastric ulcer is a serious digestive system problem and affects $5 \%$ to $10 \%$ of people during their life. Chemical antigastric ulcer drugs have side effect, cannot prevent recurrence of ulcer and also show drug interaction with many other medicaments. Tragopogon graminifolius DC.(TG) is a herb which is widely used in the west of Iran and traditionally consumed for the treatment of gastrointestinal disorders. TG was introduced as one of the most beneficial plants for digestive ulcer in Iranian traditional medicine.

Objectives: The aim of the present study was to determine the acute toxicity and protective effect of hydroalcoholic extract of TG (HeTG) against ethanol induced gastric ulcer.

Materials and Methods: Male Wistar rats were divided into five groups $(\mathrm{n}=7)$. HeTG at the doses of 50, 100, and $150 \mathrm{mg} / \mathrm{kg}$ were administered orally for 15 days and gastric ulcer was induced by pure ethanol ( $1 \mathrm{ml} / 200$ gr body weight). Ulcer index and protective rate were calculated and histological changes were determined.

Results: HeTG was nontoxic up to $2000 \mathrm{mg} / \mathrm{Kg}$. Ulcer index decreased in extract groups significantly. Protective rates of HeTG were 48.94\%, $46.39 \%$, and $43.99 \%$ in 50,100, and $150 \mathrm{mg} / \mathrm{kg}$ extract, respectively. $50 \mathrm{mg} / \mathrm{kg}$ HeTG group had higher protective effect. There was relatively normal cellular arrangement in HeTG groups.

Conclusions: TG showed protective effect against ethanol induced gastric ulcer. This study confirmed traditional medicine claims of TG.

Keywords: Gastric Ulcer; Protective Effect; Tragopogon; Traditional Medicine

\section{Background}

Gastric ulcer is the most common digestive problem in clinical examination and affects $5 \%$ to $10 \%$ of people during their life (1). Gastric ulcer is a complex and multifactorial disease with its incomplete understood etiology. It appears as a pathologic lesion in digestive tract exposed to ulcerogenic agents. This disease was seen as a result of imbalance between invasive and defensive factors $(2,3)$.

One of the external invasive factors is ethanol which, as other factors like $\mathrm{H}$. pylori infection, nonsteroidal antiinflammatory drugs (NSAIDs) and steroids, increases gastric ulcer risk. Factors involved in gastric ulcer pathogenesis are free radical production, inhibition of cell proliferations, inflammatory cell infiltrations, and production of reactive oxygen spices from lipid peroxidation and protein oxidation (3).
There are different chemical drugs for gastric ulcer prevention and treatment. Chemical gastric antiulcer drugs such as proton pump inhibitor and $\mathrm{H} 2$ receptor antagonist have side effects, cannot prevent recurrence of ulcer, and also show drug interaction with many other drugs (4). Using herbal remedies for prevention and treatment of many diseases are under development worldwide. Numerous researches on medicinal plants have been performed to recognize and classify their application for the prevention and treatment of gastric ulcer. Herbal drugs, especially those that have traditionally been consumed, are safe, clinically effective, and relatively cheaper. They also have comprehensive ability to compete with chemical drugs and are more tolerated by patients during treatment period (1).

Implication for health policy/practice/research/medical education:

This research confirmed Iranian traditional medicine claims for Tragopogon Graminifolius in treatment of peptic ulcer and gastric bleeding. Also our paper supported widespread using of this herb for treatment of gastrointestinal disorders in the west of Iran.

Copyright (C) 2013, Iranian Red Crescent Medical Journal; Licensee KowsarKowsar Ltd. This is an Open Access article distributed under the terms of the Creative Commons Attribution License (http://creativecommons.org/licenses/by/3.0), which permits unrestricted use, distribution, and reproduction in any medium, provided the original work is properly cited. 
Tragopogon graminifolius DC (TG) Known as "sheng" from Compositae (Asteraceae) family is widely consumed as a green vegetable in the west of Iran. In Iranian traditional medicine, TG is used for poison elimination and as astringent and bleeding inhibitor, wound healer, aseptic property, and liver and stomach protector. It is also used for healing digestive bleeding and pulmonary and digestive ulcer. This herb was introduced as one of the most beneficial plants for digestive ulcer in traditional medicine $(5,6)$. In different nations, Tragopogon genus is used as anticough, astringent, skin repairing (7) and is used in the treatment of gastric disorders traditionally (8).

Active constitutes of Tragopogon genus are flavonoids which consist of apigenin, luteolin, quercetin, vitexin, isovitexin, vicenin-1and 2, swertisin, orientin, isoorientin, and lucenin $(9,10)$. Some Tragopogon species have triterpene saponins like tragopogonosides A-I, (11) and vitamin C, K and E, (12) were recognized from some Tragopogon species. To our knowledge, there is no scientific report on gastric protective effects of Tragopogon graminifolius.

\section{Objectives}

The aim of the present study was to determine acute toxicity and protective effect of HeTG against ethanol induced gastric ulcer in male rats.

\section{Materials and Methods}

\subsection{Animals}

In this study, Wistar male rats with 190 - 230 gr weight were used. Animals were kept under standard laboratory conditions $\left(23 \pm 2^{\circ} \mathrm{C}, 12\right.$ light and 12 dark cycles, and standard humidity) and had free access to water and food. The ethic committees for animal study accepted the protocol of the present study. All experiments were performed in the morning.

\subsection{Plant}

TG was collected in April from west of Iran (Kermanshah province) and authenticated by Dr. F. Attar (Department of Biology, Faculty of Sciences, University of Tehran), and a voucher specimen (No.43603) deposited in the central herbarium of Tehran University. Arial parts were dried in shadow and room temperature.

\subsection{Extract Preparation}

Plant aerial parts were powdered and 100 gr of powder was minced in $400 \mathrm{ml} \mathrm{70 \%} \mathrm{ethanol.} \mathrm{After} 48$ hours, the extract was filtered and speared on a flat surface. After etha- nol evaporation, the extract was trimmed and weighted.

\subsection{Drug and Chemicals}

Ethanol (Merck, Germany) was used for the induction of gastric ulcer, and chloroform (Merck, Germany) was used for anesthetizing the animals. Omeprazole (Cipla, India) was used as the standard protection of gastric ulcer.

\subsection{Acute Toxicity of TG}

Twenty albino male mice were divided into four groups of five animals each. HeTG at single dose of 250, 500, 1000 , and $2000 \mathrm{mg} / \mathrm{Kg}$ body weight was administered to the animals of each group intraperitoneally. Animals were observed for 48 hours after HeTG administration for mortality, clinical, and physical signs of toxicity (restlessness, dullness, agitation) (13).

\subsection{Experiment Design}

Thirty five Wistar male rats were divided into 5 groups $(\mathrm{n}=7)$ including:

Group 1 (control): received distilled water (DW) $(1 \mathrm{cc} / \mathrm{kg})$ Group 2 (control positive): received Omeprazole (OMP, $10 \mathrm{mg} / \mathrm{kg})(14)$

Group 3 (extract): received HeTG extract (50 mg/kg)

Group 4 (extract): received HeTG extract (100 mg/kg)

Group 5 (extract): received HeTG extract $(150 \mathrm{mg} / \mathrm{kg}$ )

The drug and extracts were given orally for 15 consecutive days (15).

\subsection{Ethanol Induced Gastric Ulcer}

Animals had starvation for forty eight hours before ulcer induction and received DW with $1 \%$ sucrose. At day fifteen, one hour after daily regimen of DW, OMP, and extracts, animals received pure ethanol ( $1 \mathrm{ml} / 200$ gr body weight) by gavage (14).

\subsection{Macroscopic Survey}

Animals were anesthetized by chloroform one hour after ethanol administration and were dissected. Their stomach was isolated and cut along greater curvature. The stomach was cleaned and speared on a flat surface (16).

\subsection{Measurement of Ulcer Index and Calculation of Protection Rate}

Gastric ulcers were measured along longitudinal axis by geritacollis under stereomicroscope and expressed in centimeter. Each five petechial lesions were counted and 
considered as $1 \mathrm{~mm}$ of ulcer. All ulcers were summed and considered as ulcer index for each animal. Protection rate was calculated by the following formula (17).

Protection rate $(\%)=($ Control mean ulcer index - test mean ulcer index $) /($ Control mean ulcer index $) \times 100$

\subsection{Microscopic Survey}

For microscopic survey, gastric tissues were fixed in $10 \%$ formaldehyde and after processing and sectioning, microscopic slides were stained by Hematoxylin-Eosin methods. Tissue changes consisted of epithelial tissue and glands arrangement, edema, congestion, necrosis, hemorrhage, and leucocytes infiltration were evaluated (2).

\subsection{Data Analysis}

Data expressed as mean \pm SD and were analyzed by one way ANOVA and Tukey test. $\mathrm{P}<0.05$ was considered significant.

\section{Results}

\subsection{Acute Toxicity of TG}

There was no animal mortality following single dose of intraperitoneal injection of 250,500,1000, and $2000 \mathrm{mg} /$ $\mathrm{kg}$ TG extract concentrations. During observation period (48 hours), the animals did not display any clinical sign of toxicity.

\subsection{Effect of HeTG on Ethanol Induced Gastric ulcer \\ Oral gavage of ethanol induced longitudinal gastric}

ulcer in the glandular part of stomach of control group (Figure 1(b)). Ulcer index in all HeTG receiving groups (50, $100,150 \mathrm{mg} / \mathrm{kg}$ ) were lower than ethanol and Omeprazole (OMP) groups significantly $(\mathrm{P}=0.04)$ (Table 1 and Figure 2). HeTG (50 mg/kg) had the lowest ulcer index (3.40 \pm 0.69). Difference between HeTG and OMP groups was not significant. Protection rates which indicate the protective effect of HeTG against ulcer induction in all three HeTG doses were higher than those of OMP and ethanol groups. Also the highest protection rate (\%48.94) belonged to $50 \mathrm{mg} / \mathrm{kg}$ group (Table 1 ).

Figure 1. Macroscopic Photo of Dissected Stomach
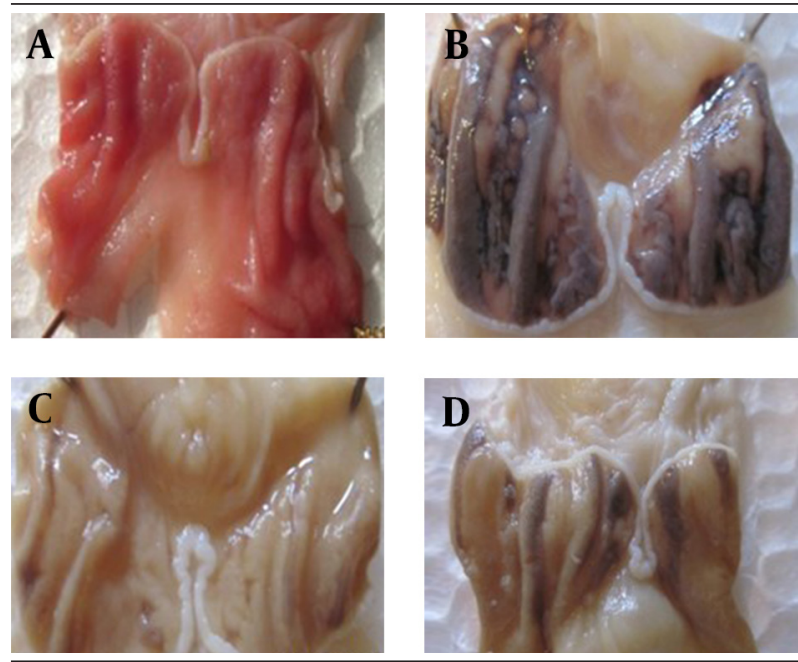

(a) Normal,(b) ethanol induced ulcer, (c) $50 \mathrm{mg} / \mathrm{kg} \mathrm{HeTG}+$ Ethanol(d) 150 mg/kg HeTG + Ethanol

Table 1. Protective Effect of HeTG on Ethanol Induced Gastric Ulcer in Rat. Ulcer Index and Protection Rate of Control and HeTG Groups Were Presented.

\begin{tabular}{llllll}
\hline Groups & Ethanol & OMP & HeTG 50 mg/Kg & HeTG 100 mg/Kg & HeTG 150 mg/Kg \\
\hline Ulcer index $(\mathbf{c m})^{\mathrm{a}}$ & $6.66 \pm 0.85$ & $3.94 \pm 0.28^{\mathrm{b}}$ & $3.40 \pm 0 / 69^{\mathrm{b}}$ & $3.57 \pm 0.67^{\mathrm{b}}$ & $3.73 \pm 0.42^{\mathrm{b}}$ \\
Protection rate(\%) & - & $40.84 \%$ & $48.94 \%$ & $46.39 \%$ & $43.99 \%$ \\
\hline
\end{tabular}

${ }^{a}$ Values express as means \pm standard deviation. The mean reference is significant at 0.05 level $(n=7)$

${ }^{b} \mathrm{P}<0.05$ compared with respective ethanol control group

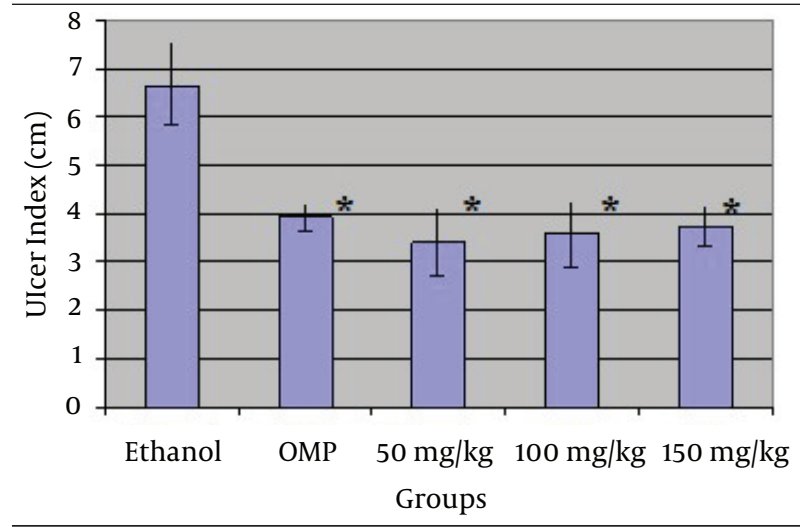

Figure 2. Ulcer index in HeTG and control groups

\subsection{Microscopic Evaluation}

Microscopic evaluation of ethanol induced gastric lesion showed severe bleeding, leucocytes and RBC infiltration, epithelial and glandular destruction, and cellular irregularity. The ulcers were limited to gastric mucosa and there were no submucosal lesions (Figure 3 (b)). HeTG decreased ethanol induced necrosis and tissue damage. In HeTG groups (especially $50 \mathrm{mg} / \mathrm{kg}$ ), cellular arrangement and vascular structure of lamina propria were relatively normal, but cellular density was less than normal status (Figure $3(\mathrm{c})$ ). 
Figure 3. Microscopic Photos of Gastric Tissue, Stained with Hematoxylin and Eosin Methods $(\times 100)$
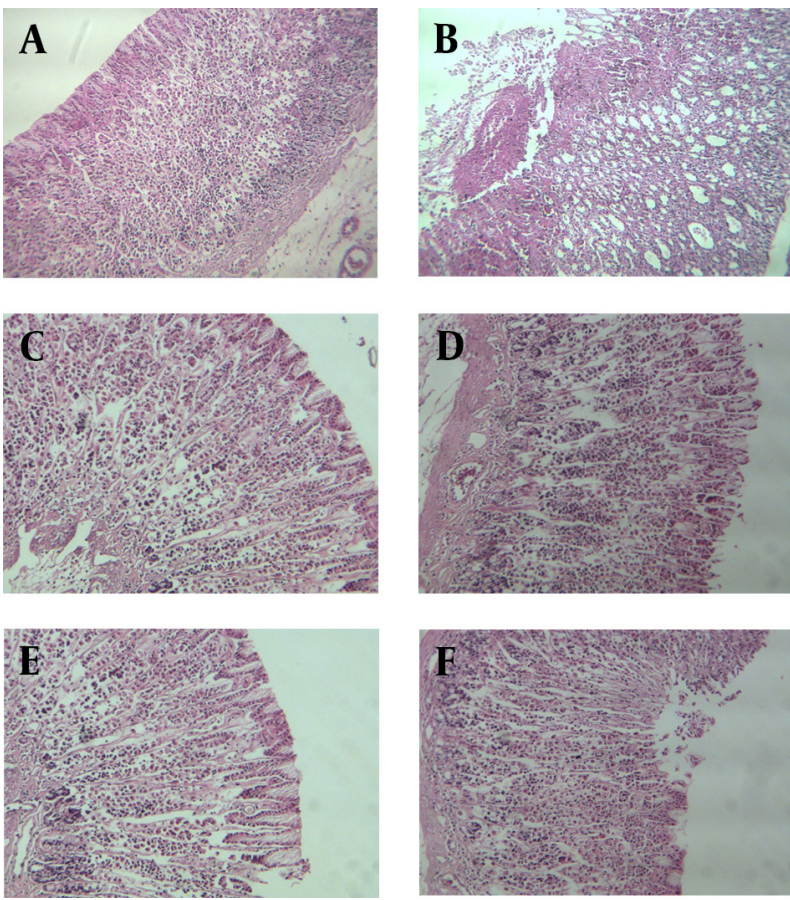

(a) normal, (b) ethanol, (c) HeTG (50 mg/kg) + Ethanol, (d) HeTG (100 mg $\mathrm{kg})+$ Ethanol, (e) HeTG (150 mg/kg) + Ethanol, (f) OMP (10 mg/kg) + Ethanol

\section{Acknowledgements}

None declared.

\section{Authors' Contribution}

Mohamad Hosein Farzaei designed original idea, contributed to the development of the protocol, collected and analyzed data, and wrote the manuscript. Mozafar Khazaei contributed to the development of the protocol, contributed to analyzing data and writing the manuscript. Zahra abasabadi contributed to the development of the protocol and wrote the draft, Maryam Feyzmahdavi and Gholamreza Mohseni contributed to the development of the protocol.

\section{Financial Disclosure}

None declared.

\section{Funding/Support}

This research originated from a Pharm D. thesis and was financially supported by Kermanshah University of Medical Sciences. We received a grant (NO.90032) from Kermanshah University of Medical Science to purchase materials and perform research practice in Fertility and
Infertility Research Center, Kermanshah

\section{References}

1. Sumbul S, Ahmad MA, Mohd A. Role of phenolic compounds in peptic ulcer: An overview. J Pharm Bioallied Sci. 2011;3(3):361-7.

2. Arun M, Asha VV. Gastroprotective effect of Dodonaea viscosa on various experimental ulcer models. Journal of Ethnopharmacology. 2008;118(3):460-465.

3. Pradeepkumar Singh L, Kundu P, Ganguly K, Mishra A, Swarnakar S. Novel role of famotidine in downregulation of matrix metalloproteinase-9 during protection of ethanol-induced acute gastric ulcer. Free Radic Biol Med. 2007;43(2):289-99.

4. Lakshmi V, Singh N, Shrivastva S, Mishra SK, Dharmani P, Mishra V, et al. Gedunin and photogedunin of Xylocarpus granatum show significant anti-secretory effects and protect the gastric mucosa of peptic ulcer in rats. Phytomedicine. 2010;17(8-9):569-74.

5. Avicenna. The cannon of medicine,.1983.

6. Aghili MH, Rahimi R, Shams Ardekani MR, Farjadmand F. Makhzanal-Advia. 2009.

7. Guarrera PM. Food medicine and minor nourishment in the folk traditions of Central Italy (Marche, Abruzzo and Latium). Fitoterapia. 2003;74(6):515-44.

8. Singh KN, Lal B. Ethnomedicines used against four common ailments by the tribal communities of Lahaul-Spiti in western Himalaya. J Ethnopharmacol 2008;115(1):147-159.

9. Kroschewsky JR, Mabry T], Markham KR, Alston RE. Flavonoids from the genus tragopogon (compositae). Phytochemistry. 1969;8(8):1495-8.

10. Sareedenchai V, Ganzera M, Ellmerer EP, Lohwasser U, Zidorn C Phenolic compounds from Tragopogon porrifolius L. Biochem Syst Ecol 2009;37(3):234-6.

11. Miyase T, Kohsaka H, Ueno A. Tragopogonosides A-I, oleanane saponins from Tragopogon pratensis. Phytochemistry. 1992;31(6):208791.

12. Vardavas CI, Majchrzak D, Wagner KH, Elmadfa I, Kafatos A. The antioxidant and phylloquinone content of wildly grown greens in Crete. Food Chemistry. 2006;99(4):813-21.

13. Khazaei M, Salehi H. Protective effect of falcaria vulgaris extract on ethanol induced gastric ulcer in rat. Iranian Journal of Pharmacology \& Therapeutics (IIPT). 2006;5(1):43-6.

14. Dharmani P, Kuchibhotla VK, Maurya R, Srivastava S, Sharma S, Palit G. Evaluation of anti-ulcerogenic and ulcer-healing properties of Ocimum sanctum Linn. J Ethnopharmacol 2004;93(2-3):197206.

15. Al-Qarawi AA, Abdel-Rahman H, Ali BH, Mousa HM, El-Mougy SA The ameliorative effect of dates (Phoenix dactylifera L.) on ethanolinduced gastric ulcer in rats. J Ethnopharmacol 2005;98(3):313-7.

16. Arslan SO, Gelir E, Armutcu F, Coskun O, Gurel A, Sayan H, et al. The protective effect of thymoquinone on ethanol-induced acute gastric damage in the rat. Nutrition research (New York, N.Y.). 2005;25(7):673-80

17. Joseph JM, Sowndhararajan K, Manian S. Protective effects of methanolic extract of Hedyotis puberula (G. Don) R. Br. ex Arn. against experimentally induced gastric ulcers in rat. J Ethnopharmacol 2010;131(1):216-9.

18. Jain KS, Shah AK, Bariwal J, Shelke SM, Kale AP, Jagtap JR, et al Recent advances in proton pump inhibitors and management of acid-peptic disorders. Bioorganic \& Medicinal Chemistry. 2007;15(3):1181-1205.

19. Guaraldo L, Sertiè JAA, Bacchi EM. Antiulcer action of the hydroal coholic extract and fractions of Davilla rugosa Poiret in the rat. $J$ Ethnopharmacol 2001;76(2):191-5.

20. Schmeda-Hirschmann G, Yesilada E. Traditional medicine and gastroprotective crude drugs. J Ethnopharmacol 2005;100(1-2):61-6.

21. Markman BEO, Bacchi EM, Kato ETM. Antiulcerogenic effects of Campomanesia xanthocarpa. J Ethnopharmacol 2004;94(1):55-7.

22. Malairajan P, Gopalakrishnan G, Narasimhan S, Veni KJK, Kavimani S. Anti-ulcer activity of crude alcoholic extract of Toona ciliata Roemer(heart wood). JEthnopharmacol 2007;110(2):348-51. 